\title{
ROBOTIC WELDING OF TUBULAR NODES
}

\author{
Ms S. Rivas University College London, UK \\ s_rivasameng.ucl.ac.uk \\ Dr A. Greig University College London, UK \\ a_greig@meng.ucl.ac.uk \\ Mr S. Blackman Cranfield University, $U K$ \\ s.blackman@cranfield.ac.uk \\ Dr W. Tizani Nottingham University, UK \\ walid.tizanianottingham.ac.uk
}

\begin{abstract}
Tubular space frames (frameworks with members orientated in 3D) are highly cfficient systems from the structural point of view. Designs using such structures are being developed for major bridges. They can provide overall cost-effective solutions, as this form can achieve a much lower weight than that of an alternative conventional stecl structure.

A major portion of the building costs is dependent on the connections, mainly the welding activity. Also, on achieving a streamlined process by which the parts of the structure can be fabricated and assembled ensuring the adequate fitting of the structure in view of the tight tolerances required for automated welding, the 3D mating of circular tubes and the compensation for distortions. The aim of the project is to improve the design, manufacture, inspection and installation of 3D stecl structures through improving the business process, automation of fabrication and the integration of all the stages in this process.
\end{abstract}

Keywords: Automated welding, space frame, complex node, laser seam tracking, FCAW.

\section{BACKGROUND}

This research covers the fields of robotics, software control and manipulation, process control, best practice assembly of tubular structures and welding processes.

The main objective is to develop an automated welding system that can locate a pipe or node joint, locate the prepared gaps and automatically complete the required weld. The system should be capable of adapting to variations in fit-up and alignment to ensure a high quality joint that satisfies structural quality requirements. The welding robot needs to be small and easily assembled/disassembled on site by one or two semi-skilled operators, with a single operator usage.

A strategy for the overall fabrication and erection of the structure will also form part of the project, encompassing design, pre-fabrication, part and full assembly, jigging, welding and inspection. Space frame construction can be found in structures such as off-shore platforms and is now being applied to bridges. A current example of a bridge to be built using this design will be the Boyne Bridge, in the Republic of Ireland, whose main span is $170 \mathrm{~m}$. Work is due to commence in mid 1999.

The research work is being carried out by Nottingham University, Cranfield University and University College London in collaboration with a group of industrial partners including MSP-Maunsell who are the technical advisors for the Boyne Bridge.

\section{INTRODUCTION}

Many bridges have plate girders with two flanges plates linked by a web plate. Old-fashioned railway bridges have a truss on either side of the tracks with cross beams. The benefit of the space frame over both of these is that it distributes the load better than a series of beams, i.e.: more members carry the live loads, which saves steel weight. Typically $50 \%$ of the structure of a plate girder bridge is dedicated to supporting itself rather than a load. For a space framc this may be reduced to $30 \%$, which means that less material is required.

However, the fabrication costs in conventional bridges are lower due to their simplicity. In these bridges all the welds are straight runs, easier and quicker to perform and automate. Hence, a significant part of the cost of building a space frame bridge resides on the fabrication and assembly of members. Space frames require a large number of complex 3D curved wclds at the nodes (intersection of tubular members). At present thesc are all done manually. The introduction of welding automation procedures provides a rcduction in overall costs of the space frame systcm.

Welding has been the number one industrial robot application since the early $1990 \mathrm{~s}$. When performed manually, spot and arc welding are subject to personnel safety hazards. Also, it is undesirable to workers because of the protective cquipment that must be worn, especially for arc welding. In addition, heavy loads are sometimes involved when 
robots are not used. Not the least important motivation to the use of robots is the quality of the finished product.

\section{AIMS AND OBJECTIVES}

\section{Project Primary objectives:}

- Development of a robotic welding equipment able to operate on or off-site and to weld complex 3D tubular welds.

- Development of intelligent adaptive control software to control the equipment for the automation of the welding process.

- Development of welding consumables, welding procedures and an adaptive control system capable of tolerating expected variations in fitup and alignment of large diameter multi-pass tubular welds.

- Investigation and development of a business process for the practical application of the fabrication and erection processes for large scale frame structures and to facilitate automation.

- Development of supporting software using KBS (Knowledge Based System) technology to manage the business process.

- To significantly reduce the fabrication time for complex tubular structures.

The development of lightweight, automated welding equipment suitable for the welding of circumferential and node joints in tubular structures is a major aim of the project. Whilst the equipment and welding procedures should be generally suitable for the welding of tubular structures; they will be specifically targeted towards the welding of nodes on bridge structures. While space frames can provide a substantial reduction on the steel required for any given span the cost savings in steel are offset by the increased complexity in fabrication. A major portion of the cost is dependent on the connections and on achieving a stream-lined process by which the parts of the structure can be fabricated and then assembled together.

To weld tubular structures is both geometrically and technologically far more demanding than the common automation of spot and single pass fillet welds. Duc to the significant sizes of bridge space frame members, the first requirement for the welding system is to be able to weld significant plate sizes in multiple passes.

\section{ORBITAL WELDING}

The most relevant technology currently used worldwide in industry is the mechanised welding of transmission pipelines as this involves similar size multi-pass orbital welds. However, the current equipment is normally welder operated and only has the capability to weld circumferential welds and not the more complex brace to chord welds. See figure 3 .

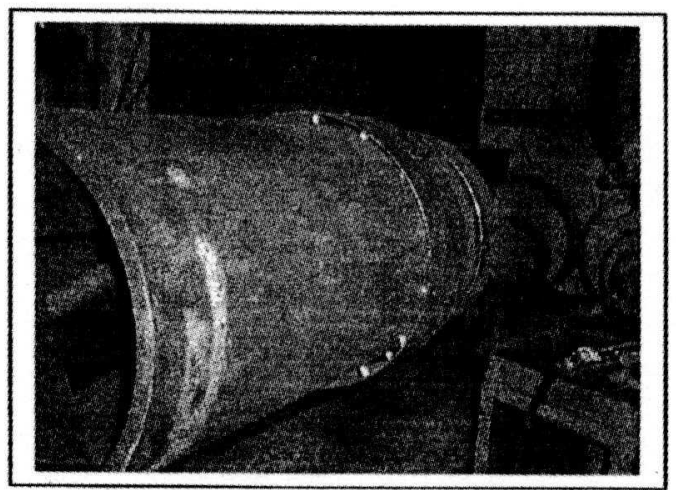

Figure 1. Guide band or track around tubular. (Cranfield University).

Additionally, pipeline welding involves the use of Gas Mctal Arc Welding (GMAW) process, which is inherently susceptible to lack-of-fusion defects that are not tolcratcd on a fatigue-loaded structure.

\section{COMPLEX NODE GEOMETRY}

The complexity of the problem arises when the particular weld is between members that are producing a complex curve weld path instead of a circle as for a typical pipe to pipe welding process. Besides, the intersection path is only the first to be followed in the so-called root run. Subsequent trajectories for the following weld passes need to be calculated using the resulting geometrical data from the previous pass and most accommodate any distortion caused by the initial weld run. Additional problems arc caused by the fact that the variation in fit-up will be significantly higher than for a pipe-topipe case, where the ends can be machined and the open end of the pipe allows access for internal alignment equipment.

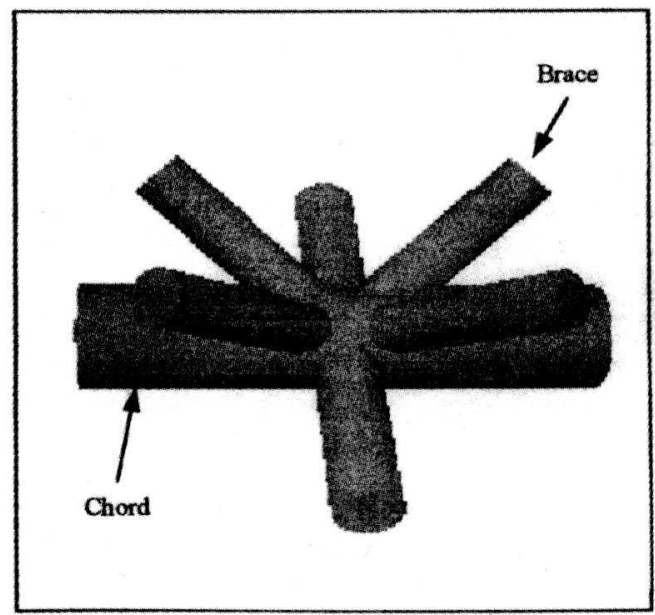

Figure 2. Complex node. 
Figure 2 shows an example of node configuration where all welds are of a non-circular shape.

The modelling of the node shown has been achieved by using application software, originally dedicated to the automated inspection of welds on the tubular members of off-shore structures [1]. This software can only output the intersection-path data of each individual joint, required for a manipulator to follow. This program needs to be extended to calculate the paths for each of the weld passes.

As an example of the weld geometry, a model of a weld from a T-node has been produced using Matlab and is shown in figure 3 .

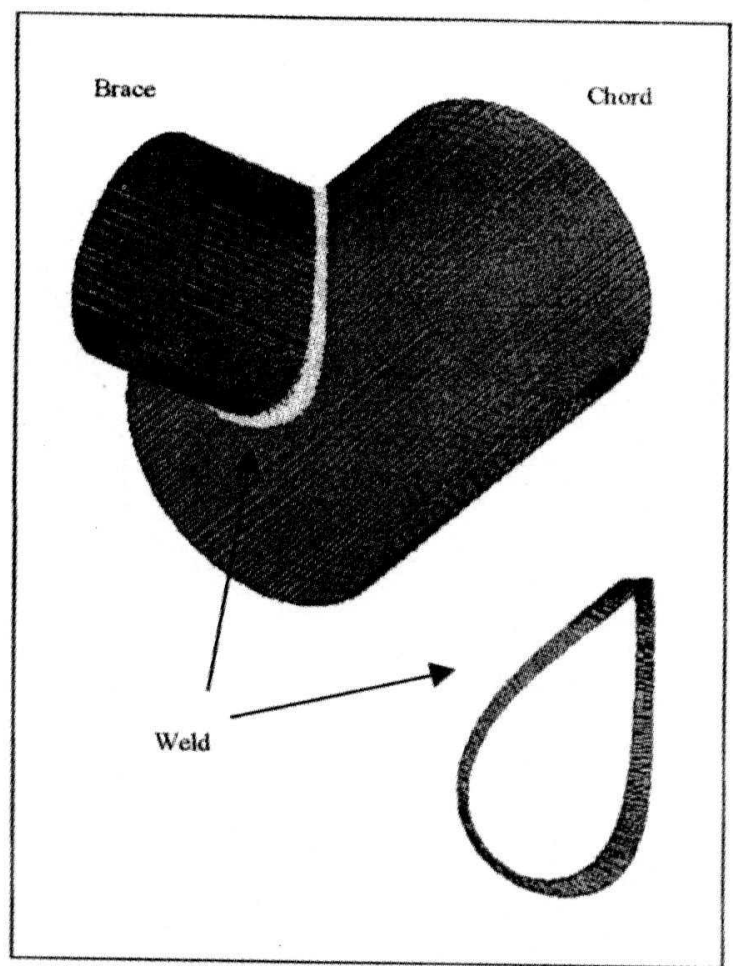

Figure 3. Typical weld geometry for a T-node.

\section{SET-UP}

In this particular project, a light weight welding head will be mountcd on a carriage, which in turn will be mounted on the brace of a particular weld. Figure 4 shows the general arrangement devised for the welding automation.

The carriage track is circular, as for orbital welding. Therefore, to access the joint all around, a traverse mechanism holding the torch in place is required. This can be achieved with a 4 degrees-of-freedom manipulator with its main link motion in the $Y$ direction shown in figure 4, parallel to the brace's longitudinal axis. The $\mathrm{z}$ axis, tilt and torch angle are used to control the movement of the tip and hence of the torch, which will have to be kept at a certain angle with respect to the surfaces being wclded; the welding head will also necd to be able to weave. The system has a further degree-of-freedom as a result of the rotation of the carriage around the brace, called $\mathrm{X}$ axis rotate. The motion controller will thercfore deal with 5 degrees-of-freedom.

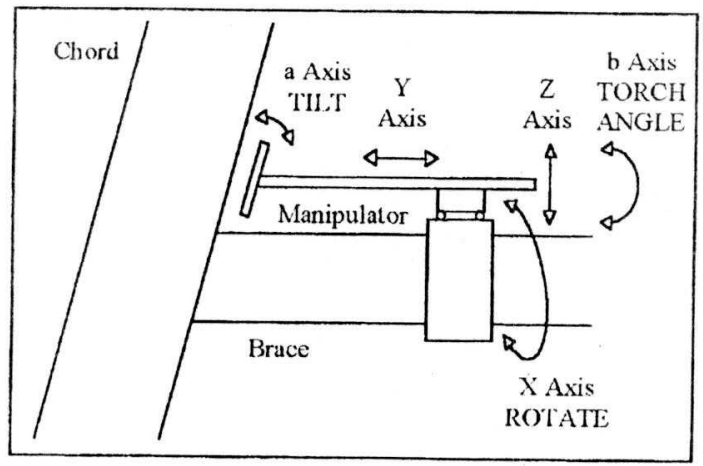

Figure 4. Overall automated welding set-up

The necessary deposition ratc and the configuration of the robot will determine the speed at which the carriage needs to be driven around the track.

\section{SEAM TRACKING}

Thermal distortion, improper preparation or poor fitup will cause changes in the joint geometry. Seam tracking is essential for welding automation in order to place the welding torch correctly and to control the welding parameters. Essential to seam tracking is some form of joint sensing to adjust the wclding torch position in real time as it moves along the weld. The two most commonly used techniques are through-the-are sensing and vision sensing. The first technique is not suitable for Flux Cored Arc Welding (FCAW), which is the welding process that will bc used. Also, through-the-arc sensing would not give the necessary information on height mismatch, root gap or presence of tacks along the joint.

Vision sensing has the advantage of sensing the environment outside the welding process but suffers from the arc light noise. In this project, a small, compact, lightwcight sensor head will be used, optically based on the structured light principle, which will minimise the effect of arc illumination. A fan of laser light emanating from one or more laser collimators strikes the surface of the work piecc. The resulting contour line is viewed by a CCD camera at a given angle (triangulation angle). The captured line contains all the neccssary information for determining the height and location of a given feature representing a scam or joint.

As shown in figure 5 , the position of the laser must be ahead of the torch and this will offer information on the immediate area to be welded. This makes it compulsory for the laser to be held at the end of the manipulator, next to the torch, which in turn makes it necessary for it to be as small and light as possible. The tracking system will be used before welding to 
measure any initial fit-up problems, and on-line, during the welding operation.

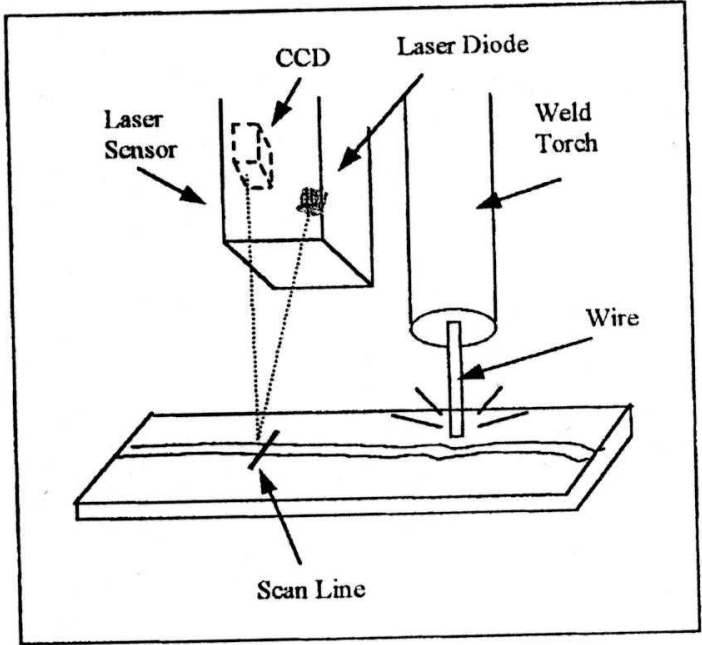

Figure 5. Laser-torch assembly.

\section{WELDING SYSTEM OVERVIEW}

It is planned that the system will integrate the following subsystems:

- Welding Head and Carriage

- Power Supply

- Tracking System

- 4 Degrees-of-Freedom Manipulator

- Motion Controller

- Monitoring of Parameters System

- Supervisory PC

- Key Pad (optional)

Figure 6 shows the overview of the system.

From the CAD Design System, information about the node will be provided to the Welding Procedure Generator. The information will include material specification, node geometry, weld type, etc. A model will break the particular weld into a number of passes, each of them having different welding parameters. The number of Weld Procedures for the whole structure will be reduced considerably as a high geometrical repetition is expected throughout.

The Welding Control System will reccive information about the number of passes and the actual pass number and geometry. Also, it will receive details on other pass requirements such as speed and oscillation (weaving), and about the head position and orientation. The Control System sends information to both power supply and motion controller. Hence, a welding operation can be performed along a pre-determined path.

To close the loop, different sensors will provide means for comparison with the reference values (e.g.: current, voltage, speed readings, etc.). With an adaptive control system, corrections on the trajectorics can be made. In the case of human supervisory control, a keypad will be used and corrections will be implemented by an operator instead of by the feedback systcm.

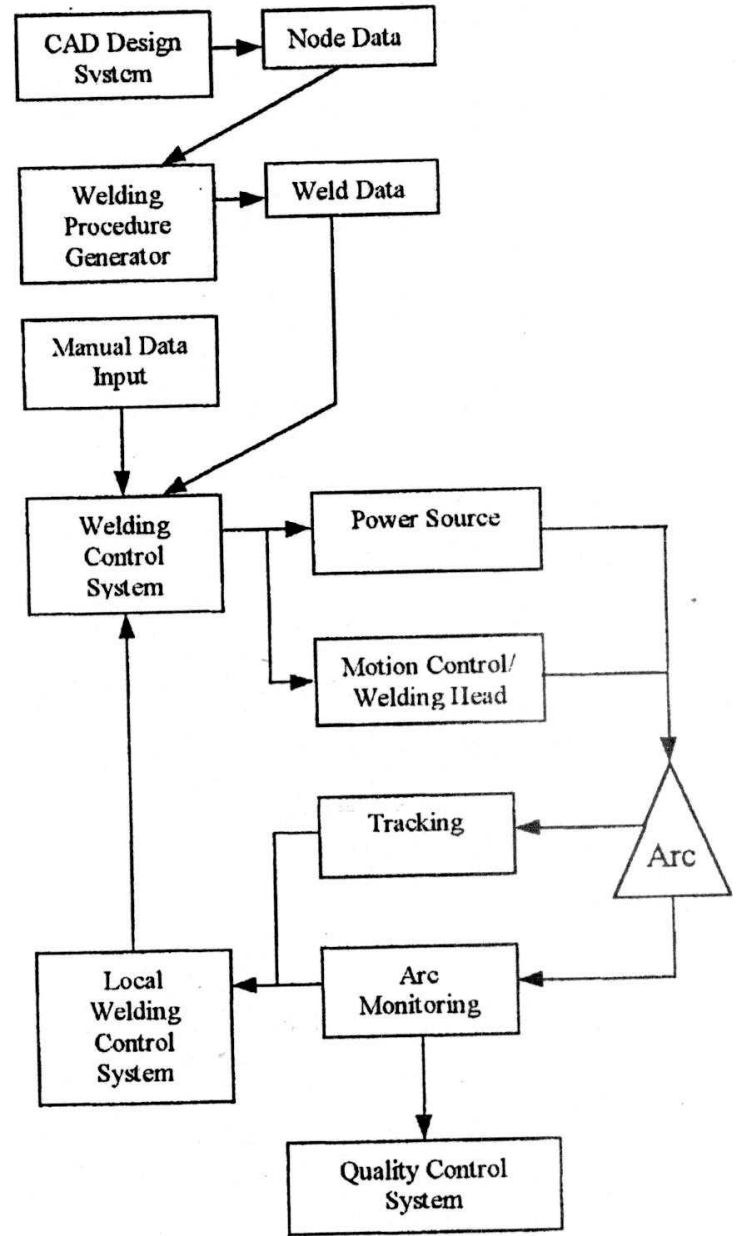

Figure 6. System overview.

Finally, a Quality Control subsystem can be added in order to assess the result. Automation should provide a much more consistent output than manual welding and it will be much easier to record the weld conditions.

\section{SUMMARY}

Tubular space frames are efficient structures and are being developed for major bridges. They offer reductions in the final structure weight and their cost is mainly due to fabrication and assembly.

The use of automated welding for the myriad complex welds, in combination with the analysis of the complete design and fabrication process, will improve the speed of the construction saving on 
labour imput and on the amount of weld material to be laid down. Figure 7 shows some graphs illustrating the production advantages of automated welding over manual and semi-automatic welding [2]. Additional benefits are improved safety, less rework and more consistent results.

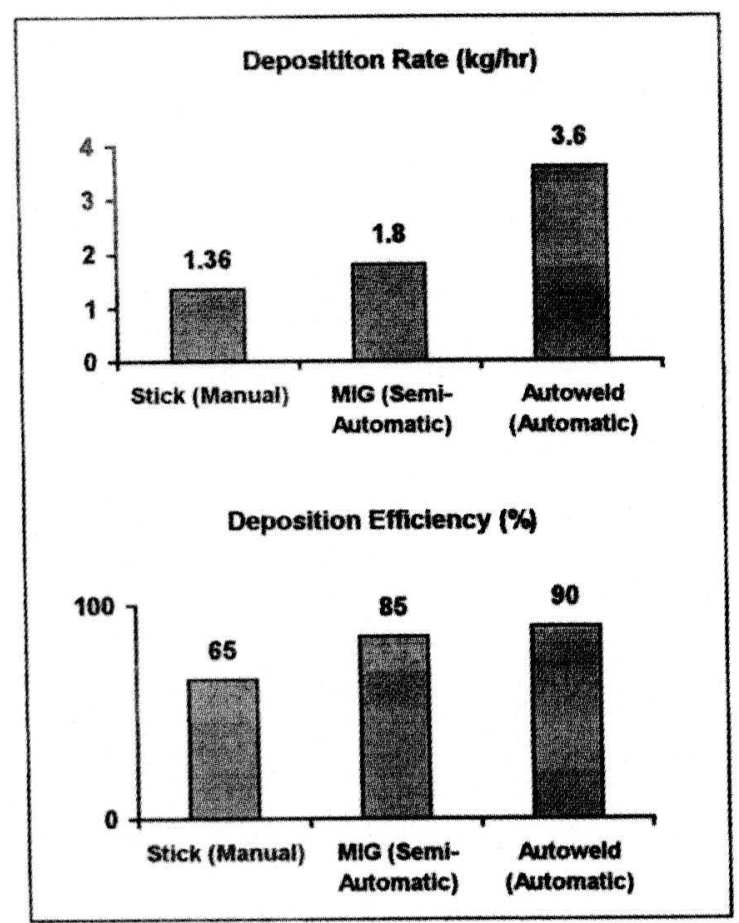

Figure 7. Comparing welding methods.

A novel lightweight robotic welding system is under development. This will include the hardware and the supporting software. The system will be capable of welding complex nodes made with connecting circular hollow sections.

Although the inspection of the welds is out of the current scope of the project, there is enormous potential for adaptation of this cquipment to an inspection task.

\section{Acknowledgements}

The authors wish to thank the rest of the project team for their contribution. They also gratefully acknowledge the EPSRC for their interest and important contribution in the funding of this research as part of the Integrated Manufacturing Initiative (IMI), with grant no. GR/M22451.

\section{Industrial project participants \\ MSP-Maunsell Ltd. Kvaerner Cleveland Bridge \\ Pipeline Induction Heat ESAB Group}

British Stcel Tubes \& Pipes

General Robotics Ltd.

Sheffield Forgemasters

Computer Services Consultant Meta Technology

Academic participants

University College London

University of Cranfield

University of Nottingham.

Web page address for the project:

http://www.nottingham.ac.uk/ evzasw/Roboweld/ .

\section{REFERENCES}

[1] A. Greig and D. Broome "Development of an underwater robotic manipulator". UCLTrans. IMarE Vol. 106, part 5, pp 217-229. 1994.

[2] CRC-Evans Auto-Weld, UK (Information obtained via personal communication). 